\title{
Fluvastatin synergistically enhances the antiproliferative effect of gemcitabine in human pancreatic cancer MIAPaCa-2 cells
}

\author{
G Bocci', A Fioravanti', P Orlandi', N Bernardini' ${ }^{2}$ P Collecchi ${ }^{3}$, M Del Tacca' and R Danesi",I \\ 'Division of Pharmacology and Chemotherapy, University of Pisa, Via Roma, I-56 I 26 Pisa, Italy; '2Department of Human Morphology and Applied Biology, \\ University of Pisa, Via Roma, I-56 126 Pisa, Italy; ${ }^{3}$ Division of Pathological Anatomy, Department of Oncology, Transplants and Advanced Technologies in \\ Medicine, University of Pisa, Via Roma, I-56I26 Pisa, Italy
}

\begin{abstract}
The new combination between the nucleoside analogue gemcitabine and the cholesterol-lowering drug fluvastatin was investigated in vitro and in vivo on the human pancreatic tumour cell line MIAPaCa-2. The present study demonstrates that fluvastatin inhibits proliferation, induces apoptosis in pancreatic cancer cells harbouring a p2 I ras mutation at codon 12 and synergistically potentiates the cytotoxic effect of gemcitabine. The pharmacologic activities of fluvastatin are prevented by administration of mevalonic acid, suggesting that the shown inhibition of geranyl-geranylation and farnesylation of cellular proteins, including p2 I rhoA and p2 I ras, plays a major role in its anticancer effect. Fluvastatin treatment also indirectly inhibits the phosphorylation of p42ERK2/mitogen-activated protein kinase, the cellular effector of ras and other signal transduction peptides. Moreover, fluvastatin administration significantly increases the expression of the deoxycytidine kinase, the enzyme required for the activation of gemcitabine, and simultaneously reduces the 5'-nucleotidase, responsible for deactivation of gemcitabine, suggesting a possible additional role of these enzymes in the enhanced cytotoxic activity of gemcitabine. Finally, a significant in vivo antitumour effect on MIAPaCa-2 xenografts was observed with the simultaneous combination of fluvastatin and gemcitabine, resulting in an almost complete suppression and a marked delay in relapse of tumour growth. In conclusion, the combination of fluvastatin and gemcitabine is an effective cytotoxic, proapoptotic treatment in vitro and in vivo against MIAPaCa-2 cells by a mechanism of action mediated, at least in part, by the inhibition of p2 I ras and rhoA prenylation. The obtained experimental findings might constitute the basis for a novel translational research in humans. British Journal of Cancer (2005) 93, 319-330. doi:I0.1038/sj.bjc.6602720 www.bjcancer.com
\end{abstract}

Published online 19 July 2005

(c) 2005 Cancer Research UK

Keywords: gemcitabine; fluvastatin; synergism; ras effectors; pancreatic cancer cells

Pancreas cancer represents a model of carcinogenesis in which the mutational activation of the k-ras oncogene is present in up to $90 \%$ of cases, and is supposed to play a relevant role in tumour progression and aggressive behaviour (Cowgill and Muscarella, 2003). Small GTP-binding proteins of the Ras superfamily, including Rho, Rab, Raf, Rac and Rap, are involved in diverse cellular functions such as cytokinesis, cell motility, cell adhesion and cell proliferation (Etienne-Manneville and Hall, 2002). Signal transduction is mediated through the activation of the p21ras as a consequence of GTP binding to the protein and through the activation of mitogen-activated protein kinases (MAPKs) belonging to the serine/threonine protein kinase family (Kolch, 2002). Before either ras and ras-related proteins can be biologically active, they undergo isoprenylation at the $\mathrm{COOH}$-terminal CAAX motif (Liang et al, 2002). Recently, the 3-hydroxy-3-methylglutarylcoenzyme A (HMG-CoA) reductase inhibitors have received great attention for their cholesterol-independent (pleiotropic) effects, such as the possible inhibition of small GTP-binding proteins Rho, Ras and Rac isoprenylation (Liao, 2002). Moreover, preclinical data seem to suggest an important role of statins as pharmacological tools for controlling abnormal cell growth, such as myocyte

\section{*Correspondence: Dr R Danesi; E-mail: r.danesi@med.unipi.it}

Received 19 May 2005; revised 20 June 2005; accepted 23 June 2005; published online 19 July 2005 or cancer cell proliferation (Kaushal et al, 2003); lovastatin and other statins suppressed the proliferation of numerous cancer cell lines, including human pancreas cancer cells, and exhibited a trigger activity in tumour-specific apoptosis (Wong et al, 2002). Holstein and Hohl (2001b) demonstrated a synergistic interaction between paclitaxel or cytosine arabinoside (Holstein and Hohl, 2001a) and lovastatin on human cancer cell lines, whereas Feleszko et al showed a potentiated antitumour activity of cisplatin (Feleszko et al, 1998) and doxorubicin (Feleszko et al, 2000) in murine tumour models when associated with lovastatin. Fluvastatin, the first entirely synthetic hydrophylic HMG-CoA reductase inhibitor, is presently used for the treatment of patients with hypercholesterolaemia (Lawrence and Reckless, 2002). It has similar efficacy and tolerability profiles than other HMG-CoA reductase inhibitors, but, unlike them, it has not been associated with rhabdomyolysis and myopathy (Scripture and Pieper, 2001). Few reports have been focused on fluvastatin inhibition of cancer cell proliferation (Seeger et al, 2003) and its possible mechanism of action (Kusama et al, 2001, 2002). To our knowledge, no combination studies have been performed with currently available chemotherapeutic drugs in order to test a hypothetic synergism with their anticancer activity and the molecular basis of the eventual positive interaction. The cytosine arabinoside analogue $2^{\prime}, 2^{\prime}$-difluorodeoxycytidine (gemcitabine) has been proven to be active in the treatment of pancreatic cancer (Abbruzzese, 2002a) 
with significant clinical benefit, but still with marginal survival advantage (El Rayes et al, 2003). Gemcitabine inhibits cell growth by interfering with the synthesis of DNA (Barton-Burke, 1999), and efforts are currently being made to increase the therapeutic efficacy of the drug in clinical settings on various types of cancer by combination with other agents, including cisplatin, oxaliplatin, irinotecan, docetaxel, 5-fluorouracil, capecitabine or pemetrexed (Heinemann, 2002; Jacobs, 2002). Moreover, numerous preclinical experimental studies have been made to enhance the antitumour effects of gemcitabine using novel therapeutic approaches such as the proteasome inhibitor bortezomib (Kamat et al, 2004) and the antiangiogenic drug SU5416 (Bocci et al, 2004).

Gemcitabine and fluvastatin do not have overlapping toxicities; therefore, the association of these compounds might be an attractive clinical alternative for the treatment of advanced pancreatic tumours. The purposes of this study are to determine: (1) the antiproliferative, proapoptotic effects of fluvastatin on $k$ ras-mutated MIAPaCa-2 human pancreatic cancer cells and its probable mechanism of action; (2) the synergistic enhancement of cytotoxicity by the combination with gemcitabine; (3) the possible underlying molecular basis of the synergism with pharmacological tools such as PD98059, a MEK1/2 inhibitor that can block activation of downstream ERK-1/2, and the expression of genes such as the deoxycytidine kinase (dCK), a rate-limiting enzyme required for the activation of gemcitabine, and the 5 -nucleotidase $\left(5^{\prime}-\mathrm{NT}\right)$, responsible for deactivation of gemcitabine; (4) the in vivo effects of the fluvastatin/gemcitabine combination on MIAPaCa-2 xenografts in nude mice.

\section{MATERIALS AND METHODS}

\section{Materials and animals}

Antipain, leupeptin, aprotinin, sodium dodecyl sulphate (SDS) and proteinase $\mathrm{K}$ were obtained from Roche Molecular Biochemicals (Mannheim, Germany). DMEM medium, foetal bovine serum (FBS), foetal calf serum (FCS), horse serum (HS), L-glutamine, penicillin, streptomycin, agarose and $180 \mathrm{bp}$ DNA ladder were from Gibco (Gaithersburg, MD, USA), swine serum was from Dako (Milan, Italy) and acrylamide was purchased from Bio-Rad (Melville, NY, USA). Diethylamine (DEA) and Nonidet P-40 were obtained from ICN Biomedicals Inc. (Costa Mesa, CA, USA); mouse IgG1 anti-p21ras monoclonal antibody was purchased from Transduction Laboratories (Lexington, KY, USA), whereas antip21rhoA and anti-p42MAPK/ERK2 rabbit polyclonal antibodies were from Santa Cruz Biotechnology Inc. (Santa Cruz, CA, USA). Horseradish peroxidase-conjugated secondary antibodies and reagents for chemiluminescence detection of proteins in immunoblots were purchased from Amersham Life Science (ECL Western detection kit, Little Chalfont, UK). Universal Mount was from Research Genetics Inc. (Huntsville, AL, USA). Quantitative realtime polymerase chain reaction (PCR) reagents were purchased from Applied Biosystems (Foster City, CA, USA). All other chemicals not listed in this section were obtained from Sigma Chemical Co. (St Louis, MO, USA). Fluvastatin (Novartis, Basel, Switzerland) and gemcitabine (Ely Lilly and Company, Indianapolis, IN, USA) were dissolved in sterile distilled water, then diluted in sterile culture medium immediately before their in vitro use, or in sterile saline solution for in vivo use. Plastic for cell culture was supplied by Costar (Cambridge, MA, USA). PD98059 was purchased from Calbiochem Biochemicals (Milano, Italy), dissolved in DMSO and diluted in culture medium.

The CD nu/nu male mice, weighing 20-25 g, were supplied by Charles River (Milan, Italy) and were allowed unrestricted access to food and tap water. Housing and all procedures involving animals were performed according to the protocol approved (approval number 11/04) by the 'Comitato di Ateneo per la sperimentazione animale' (Academic Committee for the animal experimentation) of the University of Pisa, in accordance with the European Community Council Directive 86-609, recognised by the Italian government, on animal welfare and the guidelines of the UK Co-ordination Committee on Cancer Research (UKCCCR). Each experiment employed the minimum number of mice needed to obtain statistically meaningful results.

\section{Cell culture conditions}

The human pancreatic cancer cell line MIAPaCa-2 was obtained from the American Type Culture Collection (ATCC, Manassas, VA, USA). MIAPaCa-2 cells were maintained in DMEM medium, supplemented with $10 \% \mathrm{FBS}, 2.5 \% \mathrm{HS}$, penicillin $\left(50 \mathrm{IU} \mathrm{ml}^{-1}\right)$, streptomycin $\left(50 \mu \mathrm{g} \mathrm{ml}^{-1}\right)$ and L-glutamine $(2 \mathrm{mM})$. The human colon cancer cell line COLO320-DM, a cell line with wild-type K-ras (Di Paolo et al, 2000), was from ATCC and maintained in RPMI 1640 medium supplemented with $10 \%$ FBS, penicillin and L-glutamine. Cells were routinely grown in $75 \mathrm{~cm}^{2}$ tissue culture flasks and kept in a humidified atmosphere of $5 \% \mathrm{CO}_{2}$ at $37^{\circ} \mathrm{C}$. Cells were harvested with a solution of $0.25 \%$ trypsin $-0.03 \%$ EDTA when they were in log phase of growth, and maintained at the above-described culture conditions for all experiments.

\section{Polymerase chain reaction analysis of $\mathrm{K}$-ras sequence in the MIAPaCa-2 cell line}

In order to demonstrate a possible mutation of K-ras sequence, the mutational analysis of the codon 12 of the K-ras gene was performed in MIAPaCa-2 cells by oligodeoxynucleotide hybridisation, as described previously (Marchetti et al, 1996). Briefly, as a negative control the CLONE cell line (ATCC), derived from a normal human corneal epithelium, was analysed, while as a positive control a sample of human lung adenocarcinoma with mutation at codon $12(\mathrm{GGT} \rightarrow \mathrm{TGT}$, Gly $\rightarrow$ Cys) was used. The primers used to amplify the K-ras gene around codon 12 were: $5^{\prime}$-GGCCTGCTGAAAATGACTGA- $3^{\prime}$ and $5^{\prime}$-TGATTCTGAAT TAGCTGTAT $-3^{\prime}$. The amplified products of the PCR were denatured, blotted onto nylon membranes and then hybridised with ${ }^{32} \mathrm{P}$-labelled oligonucleotide probes designed to detect ras mutations.

\section{Cytotoxicity assay}

In vitro chemosensitivity testing was performed on single-cell suspensions of MIAPaCa- 2 cells $\left(2 \times 10^{4}\right.$ cells well $\left.^{-1}\right)$ plated in sixwell sterile plastic plates and allowed to attach overnight. The treatment protocol was designed so that each drug concentration was represented by at least nine wells. Cells were treated with gemcitabine $(1-500 \mathrm{nM})$ or PD98059 $(1-100 \mu \mathrm{M})$, or fluvastatin $(0.1-20 \mu \mathrm{M})$ for $72 \mathrm{~h}$ with or without mevalonic acid $100 \mu \mathrm{M}$; in separate experiments, cells received drugs either simultaneously or sequentially as described below. Furthermore, in order to test fluvastatin antiproliferative activity on a wild-type k-ras cancer cell line, $2 \times 10^{4}$ COLO320-DM cells per well were treated with fluvastatin $(0.1-100 \mu \mathrm{M})$ for $72 \mathrm{~h}$. At the end of the experiment, cells were photographed with a phase-contrast microscope Leitz MD IL (Leica, Heerbrugg, Switzerland) and then washed with PBS, harvested with trypsin/EDTA, and counted with a haemocytometer. The survival of treated cells was expressed as a percentage of control (vehicle treated) cultures. The concentration of drugs that reduced cell survival by $50 \%\left(\mathrm{IC}_{50}\right)$ as compared to controls was calculated. Fluvastatin combined with gemcitabine was explored with three different treatment schedules at a fixed molar concentration ratio of $100: 1$ in MIAPaCa-2 cells, as follows: (A) simultaneous exposure: fluvastatin $(0.1-20 \mu \mathrm{M})$ plus gemcitabine $(1-200 \mathrm{nM})$ for $72 \mathrm{~h}$; (B) sequential exposure: fluvastatin $(0.1-$ $20 \mu \mathrm{M})$ alone for $24 \mathrm{~h}$, fluvastatin $(0.1-20 \mu \mathrm{M})$ plus gemcitabine (1-200 nM) for $24-72 \mathrm{~h}$ and gemcitabine alone for $72-96 \mathrm{~h}$; 
(C) reverse exposure: gemcitabine (1-200 nM) alone for $24 \mathrm{~h}$, gemcitabine $(1-200 \mathrm{nM})$ plus fluvastatin $(0.1-20 \mu \mathrm{M})$ for $24-72 \mathrm{~h}$ and fluvastatin $(0.1-20 \mu \mathrm{m})$ alone for $72-96 \mathrm{~h}$. Therefore, the total exposure of each drug was $72 \mathrm{~h}$. After drug exposure, the media of cell cultures were discarded and fresh medium was supplied to cells. Furthermore, PD98059 $(0.1-5 \mu \mathrm{M})$ and gemcitabine (1$50 \mathrm{~nm}$ ) were administered simultaneously for $72 \mathrm{~h}$ to the pancreatic cells at a fixed molar concentration ratio of $100: 1$.

\section{Assessement of synergism or antagonism}

To evaluate the level of interaction (synergistic, additive or antagonist) between gemcitabine and fluvastatin or PD98059, the method proposed by Chou et al (1993) was followed. Briefly, synergism or antagonism for gemcitabine plus fluvastatin or PD98059 is calculated on the basis of the multiple drug-effect equation, and quantitated by the combination index (CI), where $\mathrm{CI}<1, \mathrm{CI}=1$ and $\mathrm{CI}>1$ indicate synergism, additive effect and antagonism, respectively. Based on the classic isobologram, the CI value is calculated as:

$$
\mathrm{CI}=\left[(\mathrm{D})_{1} /\left(\mathrm{D}_{x}\right)_{1}\right]+\left[(\mathrm{D})_{2} /\left(\mathrm{D}_{x}\right)_{2}\right]
$$

At the $75 \%$ inhibition level, $\left(D_{x}\right)_{1}$ and $\left(D_{x}\right)_{2}$ are the concentrations of gemcitabine and fluvastatin or PD98059, respectively, that induce a $75 \%$ inhibition of cell growth; (D) $)_{1}$ and (D) $)_{2}$ are the concentrations of gemcitabine and fluvastatin or PD98059 in combination that also inhibits cell growth by $75 \%$ (isoeffective as compared with the single drugs alone). The dose-reduction index (DRI) defines the degree of dose reduction that is possible in combination for a given degree of effect as compared with the concentration of each drug alone:

$$
(\mathrm{DRI})_{1}=\left(\mathrm{D}_{x}\right)_{1} /(\mathrm{D})_{1} \text { and }(\mathrm{DRI})_{2}=\left(\mathrm{D}_{x}\right)_{2} /(\mathrm{D})_{2}
$$

\section{Quantitative, real-time PCR analysis of $\mathrm{dCK}$ and $5^{\prime}$-NT gene expression}

To evaluate the expression of the $\mathrm{dCK}$, a rate-limiting enzyme required for the activation of the pyrimidine analogue gemcitabine, and of the cytosolic $5^{\prime}-\mathrm{NT}$, responsible for deactivation of nucleotides and of the activated gemcitabine (Danesi et al, 2003), MIAPaCa-2 cells were treated with fluvastatin $(1$ and $5 \mu \mathrm{M})$ or vehicle alone for $72 \mathrm{~h}$. Quantitative real-time PCR analysis was performed as described previously (Giovannetti et al, 2005). Briefly, RNA $(1 \mu \mathrm{g})$ was reverse transcribed at $37^{\circ} \mathrm{C}$ for $1 \mathrm{~h}$ in a $100-\mu$ l reaction volume containing $0.8 \mathrm{~mm}$ deoxynucleotide $\mathrm{mix}$ (dNTPs), $200 \mathrm{U}$ of Moloney murine leukaemia virus reverse transcriptase (MMLV-RT), $40 \mathrm{U}$ of RNase inhibitor and $0.05 \mu \mathrm{g} \mathrm{ml}^{-1}$ random primers. The resulting cDNA was diluted $(2: 3)$ and then amplified by QRT-PCR with the Applied Biosystems 7900HT sequence detection system (Applied Biosystems). Polymerase chain reaction thermal cycling conditions, design and optimisation of primer concentrations were reported in detail by Giovannetti et al (2005). Amplifications were normalised to glyceraldehyde 3-phosphate dehydrogenase (GAPDH), and the quantitation of gene expression was performed using the $\Delta \Delta C_{t}$ calculation, where $C_{\mathrm{t}}$ is the threshold cycle; the amount of target, normalised to the endogenous control and relative to the calibrator (untreated control cells), is given as $2^{-\Delta \Delta C_{\mathrm{t}}}$.

\section{Assay of apoptosis}

The internucleosomal DNA fragmentation was assayed as reported (Danesi et al, 1995), with minor modifications. Briefly, MIAPaCa-2 cells were plated in $100 \mathrm{~mm}$ sterile dishes for cell culture and treated for $72 \mathrm{~h}$ with gemcitabine $20-200 \mathrm{nM}$, fluvastatin $0.5-20 \mu \mathrm{M}$ alone or in combination with mevalonic acid $100 \mu \mathrm{M}$, or their simultaneous combination at a fixed concentration ratio of $1: 100$ of gemcitabine/fluvastatin. Furthermore, in order to test fluvastatin proapoptotic activity on a wild-type k-ras cancer cell line, COLO320-DM cells were treated with fluvastatin $(3-50 \mu \mathrm{M})$ for $72 \mathrm{~h}$. At the end of incubation, $2 \times 10^{6}$ cells per treatment were washed with PBS, harvested with trypsin-EDTA and pelleted by centrifugation. Cells were lysed in Tris-EDTA buffer for $90 \mathrm{~min}$ at $4^{\circ} \mathrm{C}$. Cellular lysates were centrifuged at 15000 r.p.m. for $1 \mathrm{~h}$ at $4^{\circ} \mathrm{C}$, and clear supernatants containing fragmented chromatin were incubated at $42^{\circ} \mathrm{C}$ for $30 \mathrm{~min}$ in the presence of proteinase $\mathrm{K}$ $\left(200 \mu \mathrm{g} \mathrm{ml}^{-1}\right)$, and extracted by treatment with phenol:chlorofor$\mathrm{m}$ : isoamyl alcohol $(25: 24: 1)$, vigorously shaken for $30 \mathrm{~s}$ and centrifuged at 15000 r.p.m. for $10 \mathrm{~min}$. Supernatants were collected and mixed with $100 \mu \mathrm{l}$ of $\mathrm{NaCl} 5 \mathrm{M}, 1 \mathrm{ml}$ of cold $100 \%$ ethanol and $1 \mu \mathrm{l}$ of glycogen. The suspension were kept at $-20^{\circ} \mathrm{C}$ overnight to precipitate DNA fragments, then centrifuged at 15000 r.p.m. for $30 \mathrm{~min}$. Pellets were washed with $70 \%$ ethanol and dried under air flow. Samples were resuspended in Tris-EDTA buffer containing $1 \mathrm{mg} \mathrm{ml}^{-1}$ boiled bovine pancreatic RNAse $\mathrm{A}$, incubated for $1 \mathrm{~h}$ at $40^{\circ} \mathrm{C}$, and finally mixed with DNA sample buffer. Electrophoresis was performed in $1 \%$ agarose gel in Tris-EDTA-acetate buffer, and bands were visualised by ethidium bromide staining and UV transillumination. A 123-bp DNA ladder was run as a standard. Gel was photographed with a Polaroid MP4 Land camera (Polaroid, Cambridge, MA, USA) and pictures were digitised for the analysis of DNA fragmentation as described in the section 'Analysis of data'.

\section{Cell cycle analysis}

Cells were plated in $100 \mathrm{~mm}$ sterile dishes for cell culture and treated for $72 \mathrm{~h}$ with gemcitabine 1-50 $\mathrm{nM}$ or fluvastatin $0.1-10 \mu \mathrm{M}$. At the end of the experiment, cells were washed with PBS and harvested with EDTA $(0.5 \mathrm{~mm})$, centrifuged, resuspended in PBS and counted. Flow cytometry analysis of DNA content was performed in $75 \%$ ethanol-fixed cells, washed twice in $\mathrm{PBS} / 0.1 \%$ $\mathrm{NaN}_{3} / 1 \%$ FCS and filtrated through a $35 \mu \mathrm{m}$ nylon gauze filter; $1 \times 10^{6}$ cells ml $^{-1}$ were stained for $30 \mathrm{~min}$ at $4^{\circ} \mathrm{C}$ in the dark with $50 \mu \mathrm{g} \mathrm{ml}^{-1}$ propidium iodide solution containing $100 \mathrm{U} \mathrm{ml}^{-1}$ RNAse and $0.1 \%$ Nonidet P-40. Flow cytometry analysis was performed on FACSort flow cytometry apparatus (Becton Dickinson, San Jose, CA, USA), equipped with a laser for excitation at $488 \mathrm{~nm}$. CellQuest version 3.1 and ModFit LT2 version 2.0 (Verity Software House Inc., ME, USA) softwares were used for analysis of cell cycle distribution and quantitation of S-phase fraction on at least 20000 nuclei. Clumped cells, doublets and higher aggregates were gated out using electronic pulse-processing (peak vs integrated DNA fluorescence signals) and measurement accuracy was evaluated considering the coefficient of variation $(\mathrm{CV})$ of the $\mathrm{G}_{0} / \mathrm{G}_{1}$ peaks.

\section{Immunoblot analysis of p21ras, p21rhoA and p42MAPK/ERK2}

Total cellular extracts were analysed for p21ras and p21rhoA by immunoblotting. Briefly, cells exposed to fluvastatin $(2-10 \mu \mathrm{M})$ or gemcitabine $(1-50 \mathrm{nM})$ for $72 \mathrm{~h}$ alone or in combination with mevalonic acid $100 \mu \mathrm{m}$ and untreated controls were harvested with EDTA $0.5 \mathrm{mM}$, washed with PBS and centrifuged. The cells were solubilised at $4{ }^{\circ} \mathrm{C}$ in lysis buffer (Tris-base $50 \mathrm{~mm}, \mathrm{pH} 7.6,2 \mathrm{~mm}$ EDTA, $100 \mathrm{~mm} \mathrm{NaCl}, 1 \%$ Nonidet P-40, $1 \mathrm{~mm} \mathrm{PMSF}, 2 \mu \mathrm{g} \mathrm{ml}^{-1}$ aprotinin, $2 \mu \mathrm{g} \mathrm{ml}^{-1}$ pepstatin, $2 \mu \mathrm{g} \mathrm{ml}^{-1}$ antipain) for $60 \mathrm{~min}$. Cell lysate was centrifuged at 15000 r.p.m. for $20 \mathrm{~min}$ at $4^{\circ} \mathrm{C}$ and aliquots of supernatants were used to measure protein concentration. Samples were boiled for $3 \mathrm{~min}$ in SDS-sample buffer $(50 \mathrm{~mm}$ Tris-base, $\mathrm{pH}$ 6.8, 2\% SDS, $100 \mathrm{~mm}$ dithiothreitol, $10 \%$ glycerol and 
$0.025 \% \beta$-mercaptoethanol) and separated on $15 \%$ SDS-polyacrylamide gel electrophoresis (SDS-PAGE). Proteins were then transferred onto Immobilon-P membrane (Millipore, Bedford, MA, USA) and blots were probed with an anti-p21 ras (1:500) or antip21rhoA antibody $(1: 1000)$, and detected with the use of horseradish peroxidase-conjugated secondary antibody (dilution, $1: 10000)$. The membranes were then exposed to Kodak X-Omat AR film, and film densities were quantified as described in 'Analysis of data'. To evaluate the effect of fluvastatin and gemcitabine on p42MAPK/ERK2 phosphorylation, MIAPaCa-2 cells were treated with fluvastatin $(2-10 \mu \mathrm{M})$ or gemcitabine $(1-50 \mathrm{nM})$ for $72 \mathrm{~h}$ alone or in combination with mevalonic acid $100 \mu \mathrm{M}$. Cells were solubilised in lysis buffer with the protein phosphatase inhibitors sodium metavanadate and sodium fluoride (200 $\mu \mathrm{M}$ each) for $45 \mathrm{~min}$ at $4^{\circ} \mathrm{C}$, and then centrifuged at $4^{\circ} \mathrm{C}$ for $20 \mathrm{~min}$ at 15000 r.p.m. The supernatant was boiled for $3 \mathrm{~min}$ in SDS-sample buffer and separated on $11 \%$ SDS-PAGE. Proteins were transferred onto Immobilon-P membrane and probed with anti-p42MAPK/ERK2 antibody $(1: 1000)$, and detected as described above.

\section{Immunocytochemistry}

Cells were seeded onto chamberslides (Nalge Nunc, Naperville, IL, USA) at a density of $10^{4}$ per $150 \mu \mathrm{l}$; after treatment with fluvastatin at $2 \mu \mathrm{m}$ for $48 \mathrm{~h}$ or vehicle, cells were washed in PBS and fixed with $1 \%$ neutral buffered formalin $(10 \mathrm{~min})$ at $4{ }^{\circ} \mathrm{C}$. The specimens were then permeabilised with a 10 -min exposure to a solution of $0.2 \%$ Triton X-100-PBS. The samples were subsequently treated with a solution of $3 \% \mathrm{H}_{2} \mathrm{O}_{2}$ for $5 \mathrm{~min}$ to quench endogenous peroxidase activity, and nonspecific reactivity was blocked with $5 \%$ swine serum for $20 \mathrm{~min}$ at $37^{\circ} \mathrm{C}$. The samples were then incubated overnight at $4{ }^{\circ} \mathrm{C}$ in a humidified chamber with the mouse antihuman-p21rhoA or anti-human-Ha-p21 ras antibody $(1: 20-1: 50$ in $0.1 \%$ BSA-PBS). The detection protocol was carried out using biotinylated secondary antibodies and a streptavidin-peroxidase complex (LSAB kit, Dako). The reaction was developed by incubating samples in the substrate-chromogen solution $\left(1 \mathrm{mg} \mathrm{ml}^{-1} 3,3^{\prime}\right.$-diaminobenzidine tetrahydrochloride containing $0.02 \% \mathrm{H}_{2} \mathrm{O}_{2}$ ) for $5 \mathrm{~min}$ in the dark. Finally, the slides were mounted with Universal Mount and observed with a DMRB Leica microscope equipped with a $\times 100$ oil immersion lens. Each treatment was performed in three wells and observations were made from 10 fields from each well. Negative controls were obtained by substituting the primary antibodies with a nonimmune mouse serum or with $1 \times \mathrm{PBS}+0.1 \% \mathrm{BSA}$, or by using primary antibodies not raised against $\mathrm{p} 21$ rhoA or Ha-p21ras (e.g., anti-human TGF $\alpha$ immunoglobulins; Oncogene Science, Uniondale, USA). Endogenous peroxidase and avidin-binding activity were tested by incubating the slides with $3,3^{\prime}$-diaminobenzidine tetrahydrochloride alone or with streptavidin-HRP complex alone, followed by $3,3^{\prime}$-diaminobenzidine tetrahydrochloride, respectively.

\section{In vivo studies}

MIA PaCa-2 cell viability was assessed by trypan blue dye exclusion, and, on day $0,1.3 \times 10^{6} \pm 5 \%$ cells per mouse were inoculated subcutaneously between the scapulae in $0.2 \mathrm{ml}$ per mouse of culture medium without FBS using an insulin syringe with a $0.5 \times 16 \mathrm{~mm}$ needle. Animal weights were monitored and the appearance of a subcutaneous tumour that was measured every 2 days in two perpendicular directions using calipers. Tumour volume $\left(\mathrm{mm}^{3}\right)$ was defined as follows: $\left(\left(w_{1} \times w_{2} \times w_{2}\right) \times(\pi / 6)\right)$, where $w_{1}$ and $w_{2}$ were the largest and the smallest tumour diameters $(\mathrm{mm})$, respectively. The mice were randomised into groups of five. In order to treat an established tumour $\left(\sim 35 \mathrm{~mm}^{3}\right)$, at day 15 from the cell inoculum, fluvastatin, gemcitabine or their simultaneous combination was administered intraperitoneally as follows: (1) fluvastatin every 2 days at a dose of $30 \mathrm{mg} \mathrm{kg}^{-1}$ for 14 days (cumulative dose of $210 \mathrm{mg} \mathrm{kg}^{-1}$ per mouse equivalent to the study by Ferrara et al, 2003); (2) gemcitabine $120 \mathrm{mg} \mathrm{kg}^{-1}$ four times at 3-day intervals as described previously (Braakhuis et al, 1995); (3) combination treatment of fluvastatin and gemcitabine. The control group was injected i.p. with vehicle alone (saline solution). The experimental period ended 11 days after the last injection of fluvastatin and mice were killed by an anaesthetic overdose.

\section{Analysis of data}

Film densities of protein immunoblots and apoptosis assays were quantified through video imaging densitometry with the KS300 version 1.2. software (Kontron Elektronic, Eching, Germany), and expressed as arbitrary units of mean gray values (optical density), in the range of $0-255$, where 0 was black and 255 was white (Di Paolo et al, 2000). Results were expressed as the mean \pm s.e. of the optical density ratio between the gray values of isoprenylated and nonisoprenylated proteins for p21rhoA and p21ras, and between the nonphosphorylated and phosphorylated immunoblot bands for p42ERK2/MAPK. The degree of apoptosis was assessed by single-band densitometric analysis of DNA fragments in the range of $180-900 \mathrm{bp}$. The analysis by ANOVA, followed by the StudentNewman-Keuls test, was used to assess the statistical differences of data obtained in control and treated cells with respect to immunoblotting, cytotoxicity, real-time RT-PCR results and in vivo studies. $P$-values lower than 0.05 were considered significant.

\section{RESULTS}

\section{Presence of K-ras gene mutation in the MIAPaCa-2 cell line}

The analysis of DNA extracted from MIAPaCa-2 cells demonstrated a homozygous GGT $\rightarrow$ TGT mutation at codon 12 of K-ras gene, while one allele of the lung tumour sample was mutated; cells from normal cornea showed two normal alleles (Figure 1).

\section{Cytotoxicity of gemcitabine and fluvastatin}

Gemcitabine and fluvastatin inhibited cell growth of MIAPaCa-2 cell line in a concentration-dependent manner (Figure $2 \mathrm{~A}$ ), and the $\mathrm{IC}_{50}$ values were $19.7 \pm 0.4 \mathrm{~nm}$ and $1.07 \pm 0.27 \mu \mathrm{M}$, respectively. The cytotoxic activity of gemcitabine $1-500 \mathrm{~nm}$ was not modified by mevalonic acid $100 \mu \mathrm{M}\left(\mathrm{IC}_{50}=13.8 \pm 1.2 \mathrm{nM}\right.$; Figure $\left.2 \mathrm{~A}\right)$, while the antiproliferative effect of fluvastatin $0.1-20 \mu \mathrm{M}$ was greatly reduced and reversed by adding mevalonic acid $100 \mu \mathrm{M}$ in the medium (Figure 2A), as demonstrated by the $\mathrm{IC}_{50}$ value $\left(\mathrm{IC}_{50}=18.83 \pm 1.2 \mu \mathrm{M}\right)$ being significantly different from that observed in the absence of mevalonic acid $(P<0.05)$. Moreover,

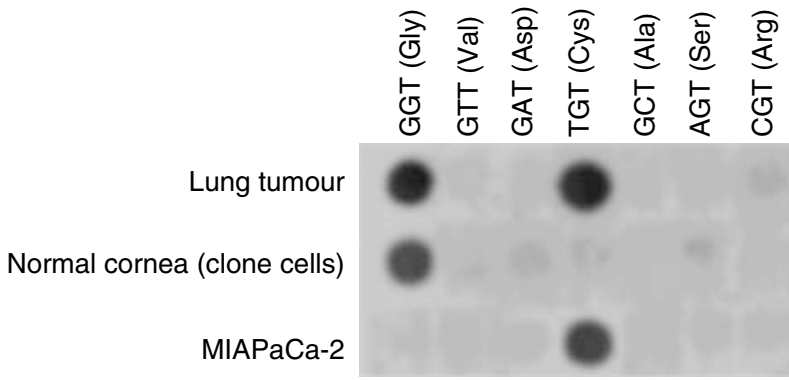

Figure I Dot-blot hybridisation analysis of point mutations (GGT $\rightarrow$ TGT) at codon 12 of the K-ras oncogene in MIAPaCa-2 and lung tumour; normal cornea (clone cell line) shows wild-type K-ras. 
A

k-ras-mutated MIAPaCa- 2 cells
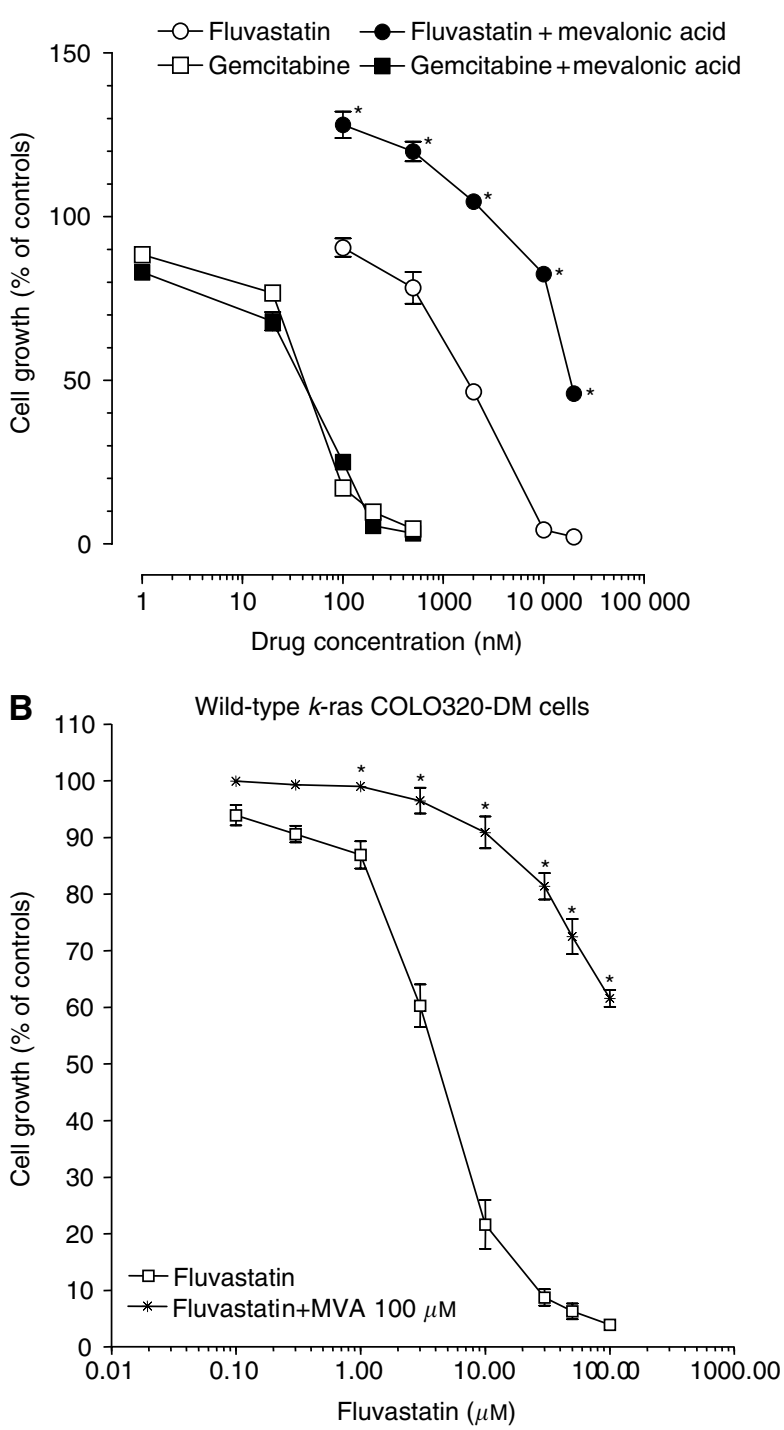

Figure 2 (A) Effect of fluvastatin, gemcitabine and their combination with mevalonic acid I00 $\mu \mathrm{M}$ on $k$-ras-mutated MIAPaCa-2 cell proliferation; (B) effect of fluvastatin and its combination with mevalonic acid I00 $\mu \mathrm{M}$ on wild-type k-ras COLO320-DM cell proliferation. Symbols and bars, mean values \pm s.e., respectively; $* P<0.05$ vs fluvastatin only.

the PD98059 72-h treatment showed an antiproliferative effect on serum-stimulated MIAPaCa-2 cells, as demonstrated by the experimental $\mathrm{IC}_{50}$ of $6.13 \pm 0.8 \mu \mathrm{m}$. In order to further test the antiproliferative activity of fluvastatin on a wild-type $k$-ras cancer cell line, COLO320-DM cells were chosen. Fluvastatin inhibited COLO320-DM cell proliferation in a dose-dependent manner (Figure $2 \mathrm{~B}$ ), and the calculated $\mathrm{IC}_{50}$ value was $4.90 \pm 0.68 \mu \mathrm{M}$. The cytotoxic activity of fluvastatin on COLO320-DM cell growth was significantly reduced by a concentration of $100 \mu \mathrm{M}$ mevalonic acid (Figure 2B).

From a morphological point of view, MIAPaCa-2 cells treated with vehicle alone grew in large colonies as confluent monolayers with an epithelial-like shape (Figure 3). Most cells treated with fluvastatin $2 \mu \mathrm{m}$ for $72 \mathrm{~h}$ became rounded and the proportion of floating cells increased in a concentration-dependent manner (Figure 3); also, gemcitabine $20 \mathrm{~nm}$ determined marked aspecific degenerative alterations of cell shape after $72 \mathrm{~h}$ (Figure 3 ).
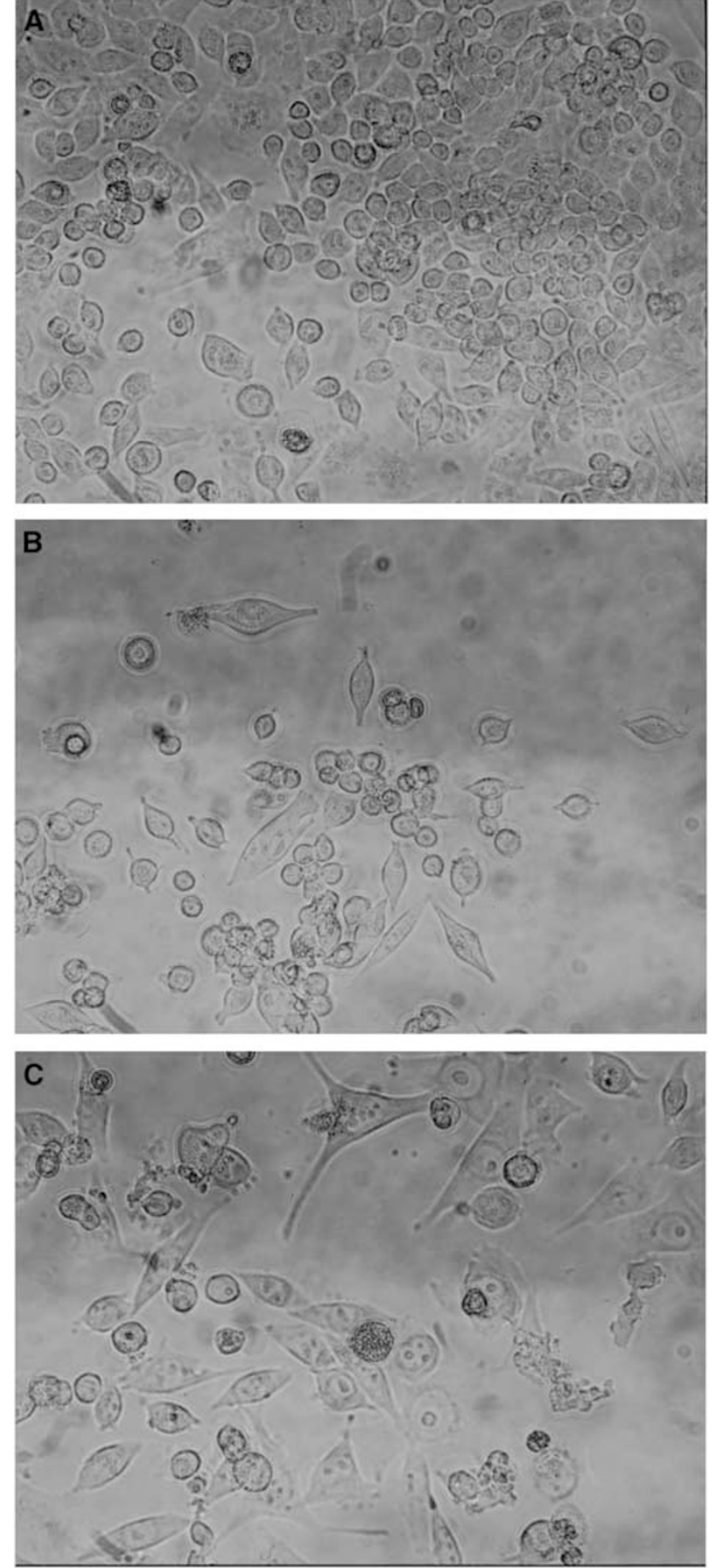

Figure 3 Microscopic pictures of control MIAPaCa-2 cells $(\mathbf{A})$ and cells treated with fluvastatin $2 \mu \mathrm{M}$ (B) or gemcitabine $20 \mathrm{nM}$ (C). Original magnification $\times 100$.

Simultaneous and sequential exposure to fluvastatin and gemcitabine showed synergism at effect levels exceeding $60 \%$ inhibition (Table 1). Synergism corresponding to $\mathrm{CI}<1$ always yielded a favourable DRI $(>1)$ for both drugs (Tables 1 and 2). The DRI values at $\mathrm{IC}_{50}, \mathrm{IC}_{75}$ and $\mathrm{IC}_{95}$ are reported in Table 2 . Figure $4 \mathrm{~A}$ shows a representative isobologram of MIAPaCa-2 cells exposed to gemcitabine and fluvastatin for $72 \mathrm{~h}$ with different schedules of treatment. Furthermore, the simultaneous treatments of gemcitabine and PD98059 for $72 \mathrm{~h}$ were synergistically active on pancreatic 
cell proliferation, as shown by a representative isobologram in Figure 4B. The position of the data points on the left of the line connecting the $\mathrm{IC}_{75}$ values of gemcitabine and fluvastatin or PD98059 indicates synergism for all schedules (Figure 4A and B).

\section{dCK and $5^{\prime}$-NT gene expression in fluvastatin-treated cancer cells}

Fluvastatin, at its 1 and $5 \mu \mathrm{M}$ concentrations, significantly increased dCK expression (e.g. at $1 \mu \mathrm{M}, 271.6 v s 100 \%$ of controls) in the MIAPaca-2 cell line, whereas, at the same concentrations, there was a significant decrease of $5^{\prime}$-NT expression (e.g. at $1 \mu \mathrm{M}$, 71.1 vs $100 \%$; Figure 5). Thus, both the simultaneous significant increase in the expression of the activating enzyme (dCK) and the decrease of the deactivating one $\left(5^{\prime}-\mathrm{NT}\right)$ suggested a possible role of fluvastatin in the activating metabolism of gemcitabine in pancreatic cancer cells.

\section{Induction of apoptosis by gemcitabine, fluvastatin and their combination}

The extent of DNA fragmentation was dependent on the concentration of both drugs (Figure 6A). In particular, the production of chromatin fragments was clearly detectable after $72 \mathrm{~h}$ in a dose-dependent manner for fluvastatin and gemcitabine (Figure 6A). The use of mevalonic acid $100 \mu \mathrm{m}$ determined a complete reversion of the apoptosis induced by fluvastatin, but not by gemcitabine, on MIAPaCa-2 cells (data not shown). Image analysis of DNA fragmentation confirmed that the increase in drug concentrations was associated with enhanced optical density of DNA bands corresponding to shorter fragments (180-900 bp; Figure 6A). A plateau was reached at the highest concentration of fluvastatin; finally, the simultaneous treatment of MIAPaCa-2 cells with fluvastatin/gemcitabine at the $100: 1$ concentration ratio was associated with a marked increase in apoptosis (Figure 6A). The concentration-dependent proapoptotic effects of $72 \mathrm{~h}$ fluvastatin treatment were confirmed also in the wild-type $k$-ras COLO320DM cancer cell line (Figure 6B).

Table I Cl values for the three drug combinations at 75, 90 and $95 \%$ levels of inhibition of MIA PaCa-2 cell growth

\begin{tabular}{lccc}
\hline & \multicolumn{3}{c}{ Cl values (mean \pm s.e.) } \\
\cline { 2 - 4 } Drug combination & $\mathbf{7 5 \%}$ & $\mathbf{9 0 \%}$ & $\mathbf{9 5 \%}$ \\
\hline Fluvastatin+gemcitabine & $0.54 \pm 0.03$ & $0.26 \pm 0.01$ & $0.16 \pm 0.01$ \\
Fluvastatin $\rightarrow$ gemcitabine & $0.66 \pm 0.04$ & $0.33 \pm 0.02$ & $0.22 \pm 0.01$ \\
Gemcitabine $\rightarrow$ fluvastatin & $0.62 \pm 0.01$ & $0.29 \pm 0.004$ & $0.18 \pm 0.002$ \\
\hline
\end{tabular}

Arrows indicate the sequence of treatment.

\section{Cell-cycle-specific effects of gemcitabine and fluvastatin}

The DNA histograms obtained from MIAPaCa-2 cells treated with fluvastatin or gemcitabine showed a dose-dependent drug effect on the cell cycle distribution (Figure 7). When the treatment with fluvastatin was prolonged up to $72 \mathrm{~h}$, the $\mathrm{G}_{2} / \mathrm{M}$ peak declined

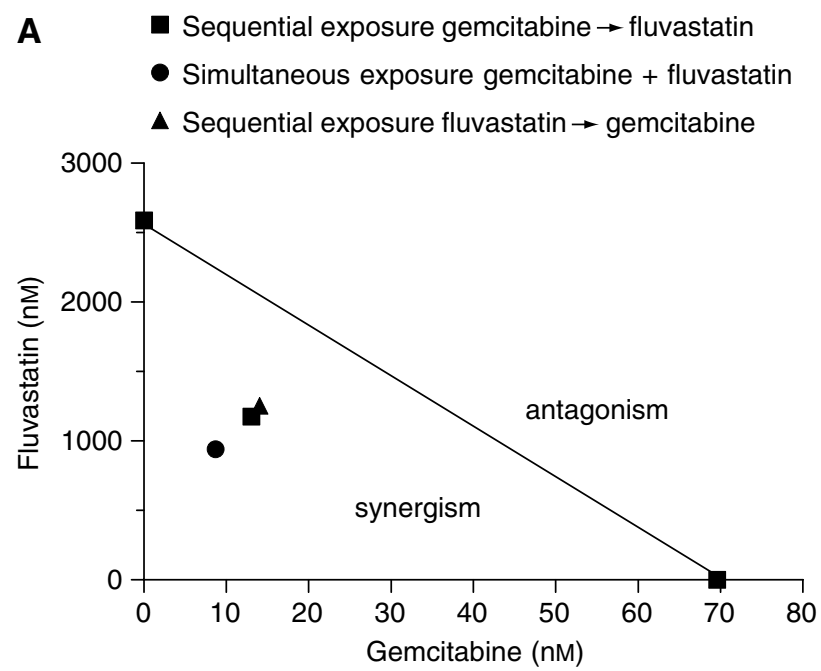

B - Simultaneous exposure gemcitabine + PD098059

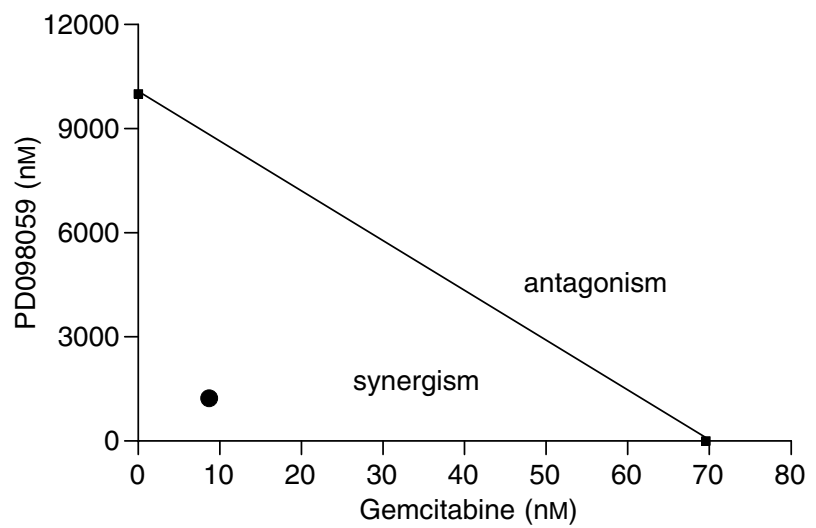

Figure 4 Isobologram analysis of MIAPaCa-2 cell growth inhibition by (A) gemcitabine and fluvastatin simultaneously and sequentially, and (B) gemcitabine and PD098059 simultaneously. The $\mathrm{IC}_{75}$ values of each drug are plotted on the axes; the solid line represents the addictive effect, while the points representing the concentrations of gemcitabine and fluvastatin or PD098059 resulting in 75\% growth inhibition of the combination are reported on the left of the connecting line, indicating synergism.

Table 2 DRI values for the three combinations at 75, 90 and 95\% levels of inhibition of MIA PaCa-2 cell growth

\begin{tabular}{|c|c|c|c|c|c|c|}
\hline \multirow[b]{3}{*}{ Drug combination } & \multicolumn{6}{|c|}{ DRI values (mean \pm s.e.) } \\
\hline & \multicolumn{2}{|c|}{$75 \%$} & \multicolumn{2}{|c|}{$90 \%$} & \multicolumn{2}{|c|}{$95 \%$} \\
\hline & Fluvastatin & Gemcitabine & Fluvastatin & Gemcitabine & Fluvastatin & Gemcitabine \\
\hline Fluvastatin+gemcitabine & $7.05 \pm 0.37$ & $2.53 \pm 0.13$ & $4.81 \pm 0.24$ & $19.29 \pm 0.97$ & $7.45 \pm 0.36$ & $38.25 \pm 1.84$ \\
\hline Fluvastatin $\rightarrow$ gemcitabine & $5.78 \pm 0.36$ & $2.08 \pm 0.13$ & $3.47 \pm 0.22$ & $14.98 \pm 0.88$ & $5.58 \pm 0.31$ & $28.63 \pm 1.60$ \\
\hline Gemcitabine $\rightarrow$ fluvastatin & $6.09 \pm 0.11$ & $2.19 \pm 0.04$ & $4.26 \pm 0.07$ & $17.07 \pm 0.27$ & $6.67 \pm 0.13$ & $34.41 \pm 0.51$ \\
\hline
\end{tabular}

Arrows indicate the sequence of treatment. 


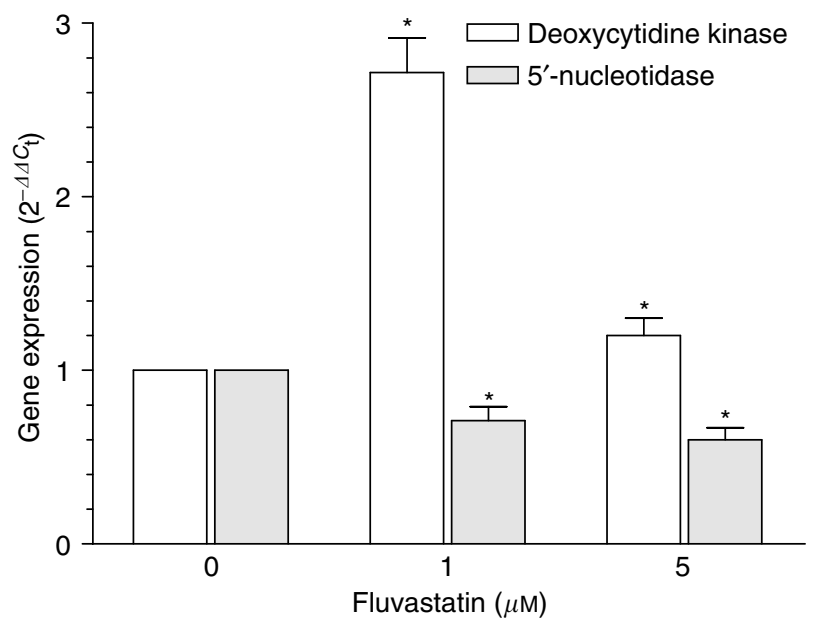

Figure 5 Deoxycytidine and $5^{\prime}-N T$ expression in fluvastatin-treated MIAPaCa-2 cancer cells. Columns, mean values obtained from three independent experiments; bars, \pm s.e.; *, statistically different from control cells $(P<0.05)$.

concomitantly to the appearance of a dose-dependent subdiploid peak (sub $\mathrm{G}_{1}$ ), typical of apoptotic cells, starting from a concentration of $2 \mu \mathrm{M}$ (Figure 7). Gemcitabine induced an S-phase accumulation of cells after $72 \mathrm{~h}$ of treatment, with the simultaneous appearance of the subdiploid peak, starting at $20 \mathrm{~nm}$ (Figure 7). Apoptosis was quantified and measured as the percentage of subdiploid cells on the DNA histogram. Both fluvastatin and gemcitabine caused a significant dose-dependent increase in apoptosis $(P<0.05$; Figure 7$)$, thus confirming the data obtained from agarose gel electrophoresis.

\section{Inhibition of p21rhoA and p21ras prenylation and phosphorylation of p42MAPK/ERK2 by fluvastatin}

Immunoblots of MIAPaCa-2 cells demonstrated that fluvastatin inhibited the post-translational processing of immature p21rhoA, causing the appearance of nongeranyl-geranylated p21rhoA proportional to the drug concentrations (Figure $8 \mathrm{~A}$ ). The image analysis of protein bands, computed as the ratio between the mean gray values of the prenylated $v s$ nonprenylated band on Western blots of p21rhoA, confirmed that fluvastatin significantly increased the amount of immature, nonisoprenylated protein in a concentration-dependent manner (Figure 8A). The cells treated simultaneously with fluvastatin and $100 \mu \mathrm{m}$ mevalonic acid presented only the band corresponding to the geranyl-geranylated protein. In contrast, gemcitabine, with or without mevalonic acid $100 \mu \mathrm{M}$, did not affect the geranyl-geranylation of p21rhoA on immunoblots (Figure 8A). In addition to this, fluvastatin determined the same concentration-dependent effects on p21ras, as shown by the appearance of a band shift representing the nonfarnesylated peptide (Figure $8 \mathrm{~B}$ ), as confirmed by image analysis (Figure $8 \mathrm{~B}$ ). Compared to controls, gemcitabine did not affect protein mobility in immunoblots due to inhibition of protein prenylation; on the contrary, the simultaneous treatment of fluvastatin with $100 \mu \mathrm{M}$ mevalonic acid markedly reduced the nonfarnesylated bands (Figure 8B). Furthermore, fluvastatin reduced the amount of the active, phosphorylated form of p42MAPK/ERK2 (Figure 8C), and the optical density ratio of phosphorylated/nonphosphorylated p42MAPK/ERK2 protein bands of treated cells appeared significantly decreased $(P<0.05$; Figure $8 C)$. Mevalonic acid contrasted the concentration-dependent effects of fluvastatin, whereas gemcitabine did not affect the ras prenylation (Figure $8 \mathrm{C}$ ).
A Fluvastatin $(\mu \mathrm{M})$ \begin{tabular}{llllll}
\hline 10 & 5 & 2 & 0.5 & $C$ & St
\end{tabular}
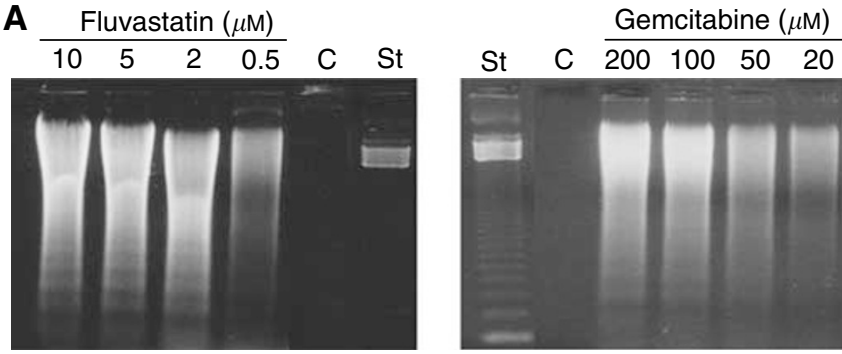



$\square$ Gemcitabine

o Fluvastatin

$\Delta$ Gemcitabine + fluvastatin

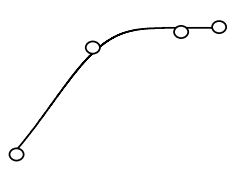$$
1
$$

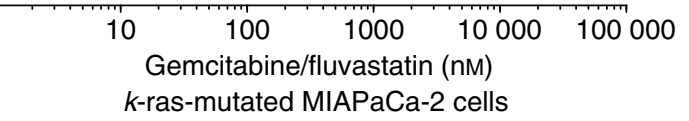

B

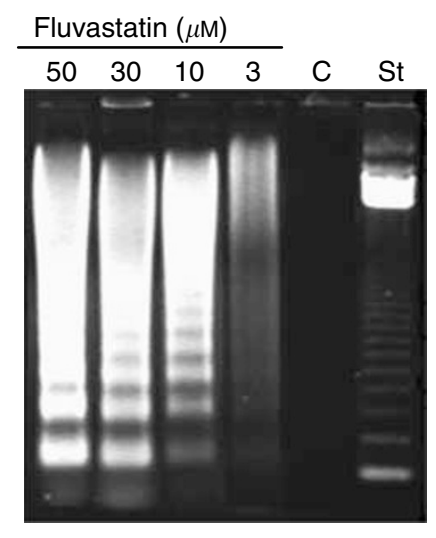

Wild-type $k$-ras COLO320-DM cells

Figure 6 (A) Gel electrophoresis of DNA extracted from fluvastatinand gemcitabine-treated $k$-ras-mutated MIAPaCa-2 cells (upper). Image analysis of apoptotic DNA from cells exposed to fluvastatin, gemcitabine and their combination (lower); (B) gel electrophoresis of DNA extracted from $72 \mathrm{~h}$ fluvastatin-treated wild-type k-ras COLO320-DM cells. C, control; St, standard ladder.

\section{Immunocytochemical localisation of p21rhoA and p21ras proteins}

Untreated MIAPaCa-2 cells showed a higher degree of immunoreactivity compared to fluvastatin-treated cells. A specific p21rhoA positivity was localised along the plasma membrane and the peripheral cytoplasmic boundaries of control cells (Figure 9A). In contrast, fluvastatin-treated cells displayed only a weak positivity homogeneously localised within the cytoplasm without specific immunostaining at the level of cell membranes (Figure 9B). Concerning anti-p21ras, the highest immunoreactivity was observed in control cells along the plasma membranes, with a faint immunostaining in their cytoplasm (Figure 9C). On the contrary, most of the fluvastatin-treated cells displayed a weak anti-p21ras immunoreaction localised mainly in the cytoplasm (Figure 9D); no specific localisation of the p21 ras peptide was observed at the level of the plasma membranes or nuclei. 

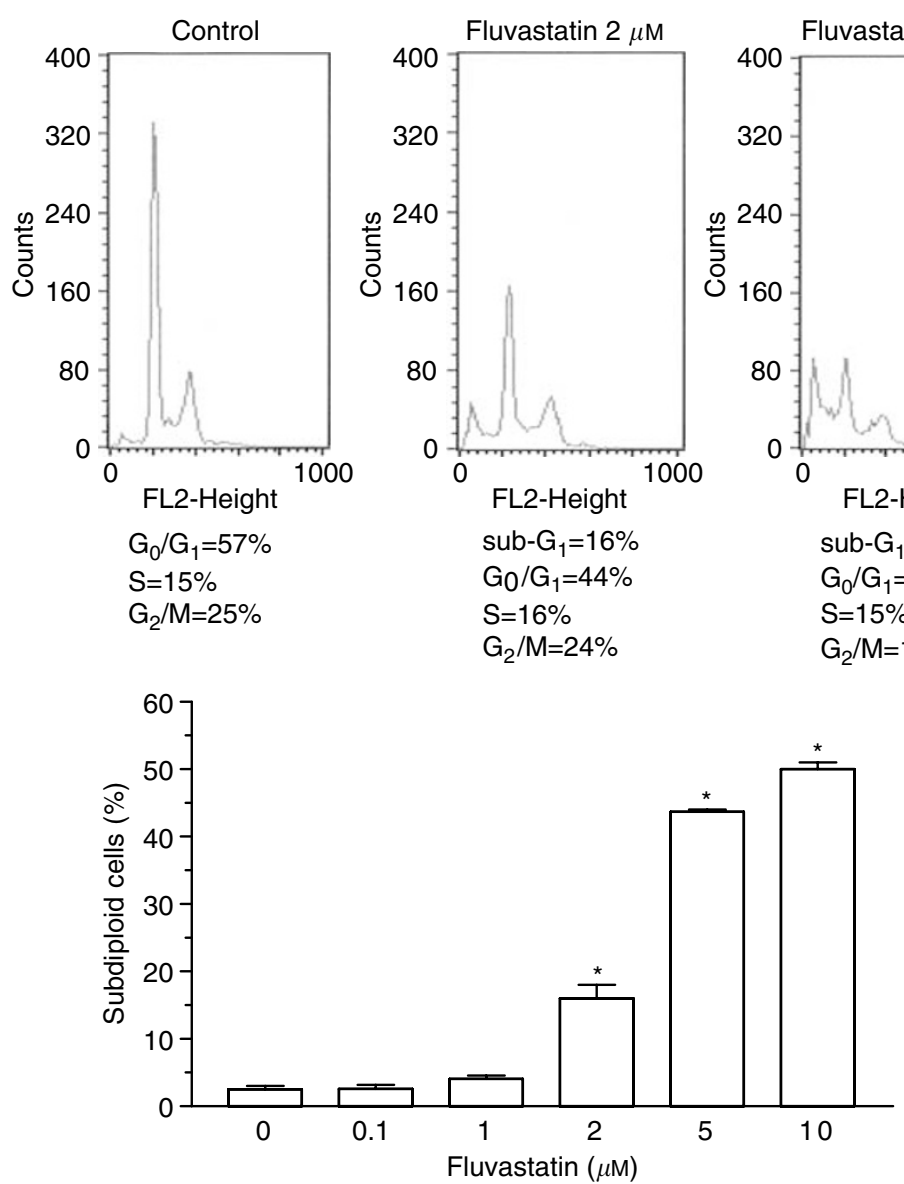

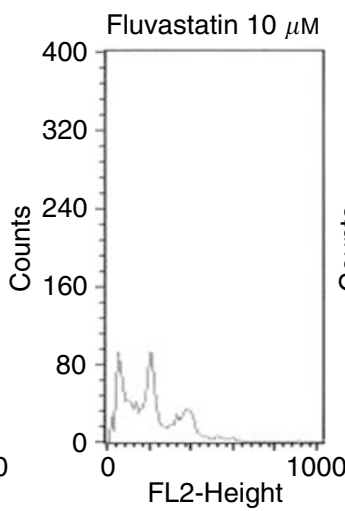

sub- $\mathrm{G}_{1}=50 \%$ $\mathrm{G}_{0} / \mathrm{G}_{1}=24 \%$ $S=15 \%$ $\mathrm{G}_{2} / \mathrm{M}=11 \%$
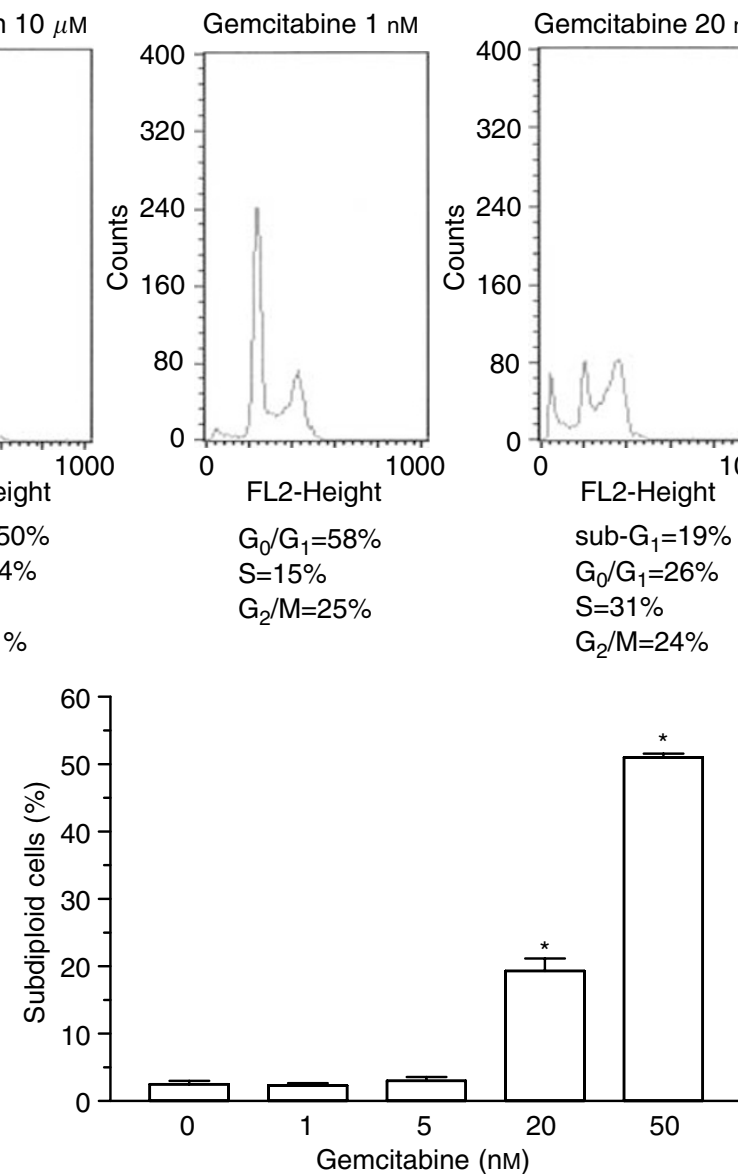

Figure 7 In vitro effect of fluvastatin and gemcitabine on cell cycle distribution of MIAPaCa-2 cells. Percent values of cells in different phases of the cell cycle are given in each panel. The subdiploid peak in DNA histograms from treated cells indicates the occurrence of apoptosis (upper). The amount of subdiploid, apoptotic cells raises as the concentrations of the drugs in the culture media increase (lower). Columns and bars, mean values \pm s.e., respectively. $* P<0.05$ vs controls.

Enhanced inhibition of tumour growth in vivo by the simultaneous combination of fluvastatin and gemcitabine

MIAPaCa-2 cells injected s.c. in $\mathrm{CD}$ nu/nu mice grew quite rapidly and tumour masses became detectable 9 days after xenotransplantation. Tumours in control animals showed a progressive enlargement in their dimensions, and a mean volume of $\sim 550 \mathrm{~mm}^{3}$ was reached at the end of the experimental period (Figure 10A). Both fluvastatin and gemcitabine were able to inhibit tumour growth, although to different extents, and their therapeutic effect was significant starting on the 19th day after implant as compared to controls (Figure 10A). In the group of animals receiving the combined treatment with fluvastatin and gemcitabine, the reduction in tumour growth was significant already on day 19 with respect to controls (Figure 10A). The tumour growth curve of fluvastatin + gemcitabine showed a significant decrease during the 14-day schedule, divergent from that of controls, as well as from fluvastatin- and gemcitabine-treated animals, and at days 22 and 27 the tumour volume was significantly different from that of controls and of animals given fluvastatin and gemcitabine alone, respectively (Figure 10A). It is noteworthy that the combination of fluvastatin and gemcitabine resulted in an almost complete regression of tumour volumes (Figure 10A). Interestingly, all the drug schedules showed tumour relapses in all the treated groups at the end of the experiments, but with a significant delay in the case of the combination treatment. The toxicity profile was favourable and acceptable for both single and combination treatment, with no loss of weight throughout the course of the experiment (Figure 10B).

\section{DISCUSSION}

The present study shows that fluvastatin inhibits proliferation, induces apoptosis in both human pancreatic cancer MIAPaCa-2 cells harbouring a p21ras mutation at codon 12 and in wild-type kras COLO320-DM cancer cells (although in different extent), and synergistically potentiates the cytotoxic effect of gemcitabine on these cancer cells. The pharmacologic effects of fluvastatin are prevented by treatment with mevalonic acid, suggesting that the demonstrated inhibition of geranyl-geranylation and farnesylation of cellular proteins, including p21rhoA and p21ras, plays a major role in its anticancer effect. Fluvastatin treatment also indirectly inhibits the phosphorylation of p42ERK2/MAPK, the cellular effector of ras and other signal transduction peptides. Indeed, a similar synergistic effect against cancer cell proliferation is obtained combining gemcitabine and PD98059, a MEK1/2 inhibitor that can block activation of downstream ERK-1/2 (Boucher et al, 2000), confirming the importance of this signal pathway in the observed experimental data. Moreover, fluvastatin treatments simultaneously increase the expression of the $\mathrm{dCK}$, the enzyme required for the activation of gemcitabine, and reduce the $5^{\prime}$-NT, responsible for deactivation of gemcitabine, suggesting a possible additional role of these enzymes in the enhanced cytotoxic 
A

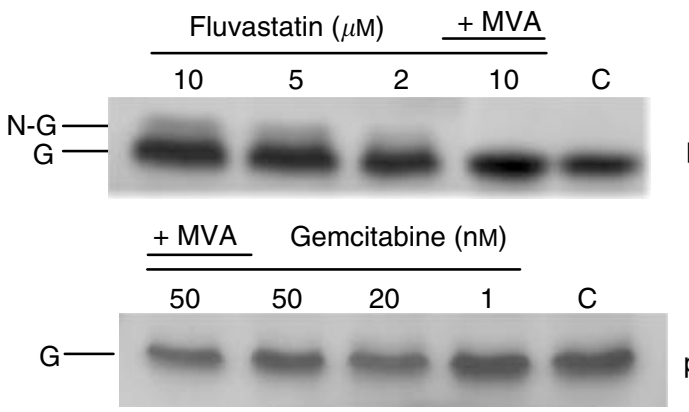

p21rhoA

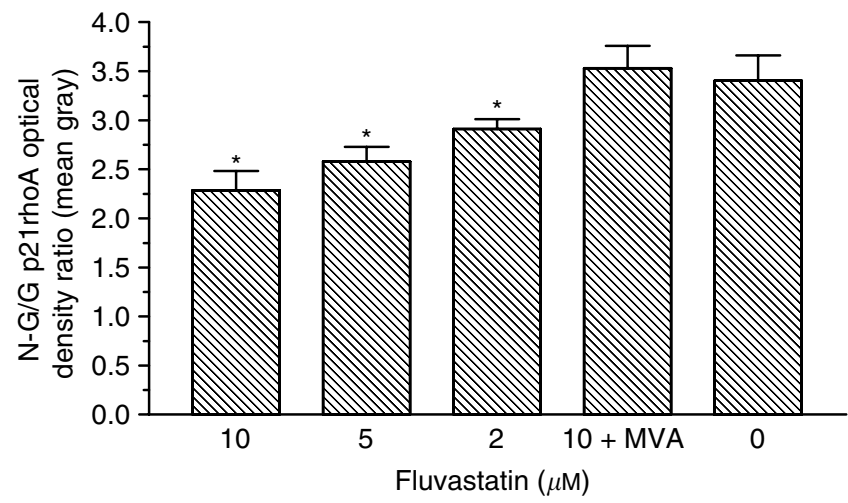

21rhoA
B
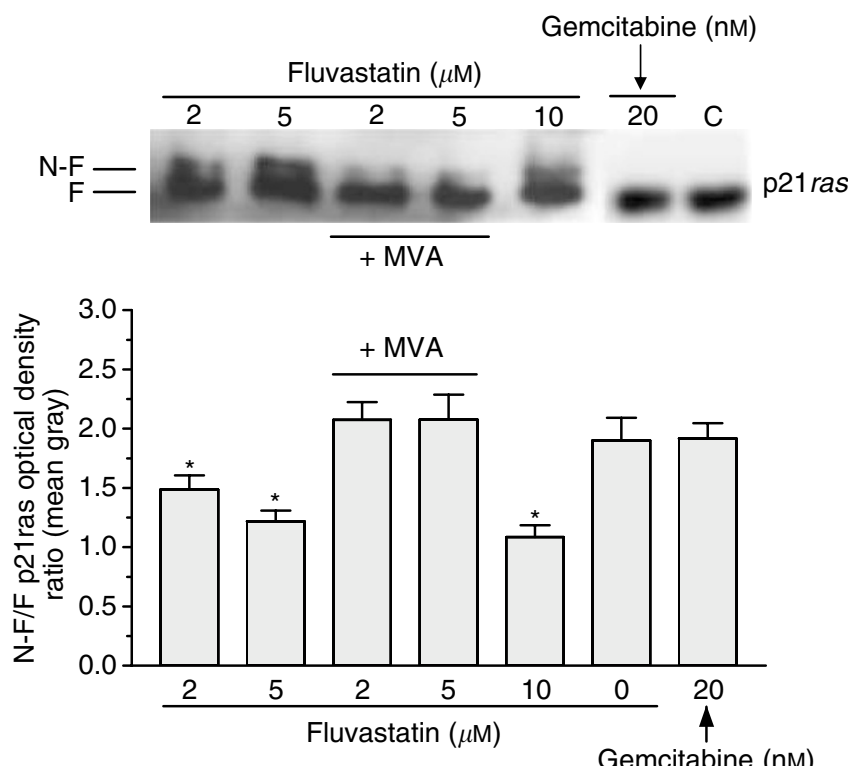

C

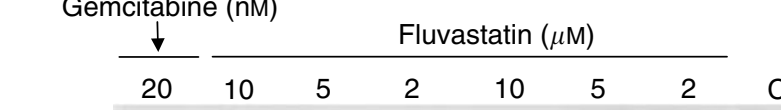
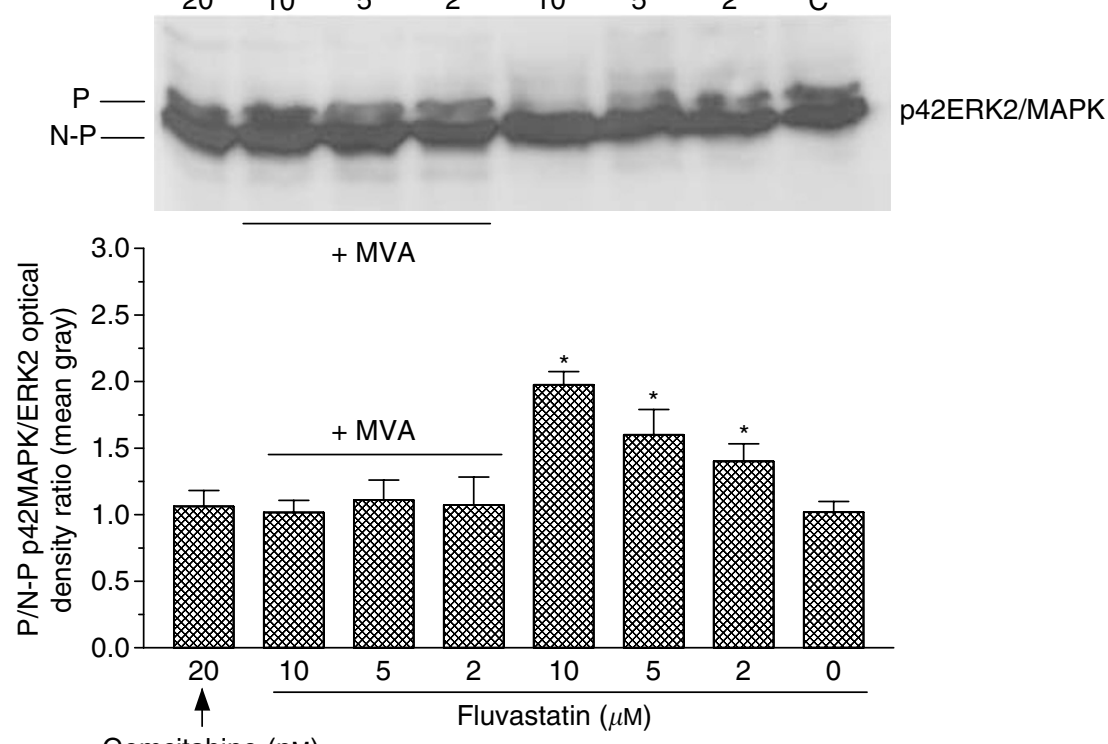

Gemcitabine (nM)

Figure 8 (A) Immunoblotting (upper) and image analysis (lower) of p2I rhoA from total cellular lysates of MIAPaCa-2 cells treated with fluvastatin and gemcitabine. Columns and bars, mean values \pm s.e., respectively. MVA, mevalonic acid, G, geranyl-geranylated, N-G, nongeranyl-geranylated p2IrhoA; ${ }^{*} P<0.05$ vs controls. (B) Immunoblotting (upper) and image analysis (lower) of p2I ras from total cellular lysates of MIAPaCa- 2 cells treated with fluvastatin and gemcitabine. Columns and bars, mean values \pm s.e., respectively. MVA, mevalonic acid, F, farnesylated, N-F, nonfarnesylated p2I ras; $* P<0.05$ vs controls. (C) Immunoblotting (upper) and image analysis (lower) of p42MAPKJERK2 in MIAPaCa-2 cells treated with fluvastatin and gemcitabine. Columns and bars, mean values \pm s.e., respectively. MVA, mevalonic acid, P, phosphorylated, N-P, nonphosphorylated p42MAPK/ERK2; *P $<0.05$ vs controls,

activity of gemcitabine in the combined treatment. Above all, the described in vitro effects were confirmed in vivo, with a significant enhancement of antitumour activity of the simultaneous administration of fluvastatin and gemcitabine.

Most studies of single-agent chemotherapy in patients with advanced adenocarcinoma of the pancreas showed low response rate and little impact on patient survival (Abbruzzese, 2002b). Ras oncogene is very frequently mutated in human pancreatic cancer, and its overexpression may be related to the neovascular and metastatic process (Rak and Kerbel, 2001). Therefore, the identification of new compounds able to affect ras and ras-related functions, in association with gemcitabine, one of the most active 

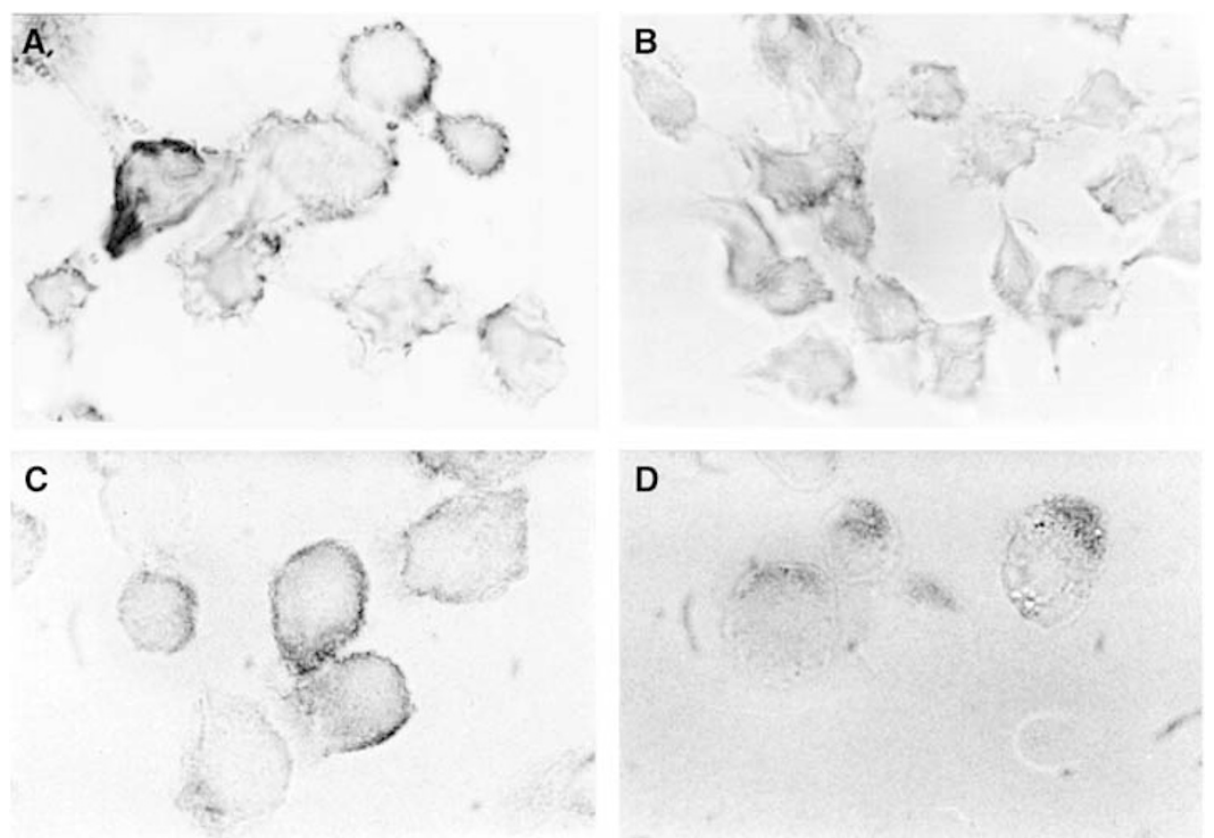

Figure 9 Immunohistochemical localisation (dark staining) of p2I rhoA in MIAPaCa-2 cells control (A) and treated with fluvastatin (B), and p2I ras in control cells $(\mathbf{C})$ and treated with fluvastatin $(\mathbf{D})$. Original magnification $\times 200$.


Figure 10 (A) Chemotherapeutic effect of gemcitabine $120 \mathrm{mg} \mathrm{kg}^{-1}$ i.p. four times at 3 -day intervals and fluvastatin $30 \mathrm{mg} \mathrm{kg}^{-1}$ i.p. every 2 days alone or in combination on MIAPaCa-2 tumours xenotransplanted in CD nu/nu mice. $* P<0.05$ with respect to controls; $* * P<0.05$ vs gemcitabine and fluvastatin alone. Symbols and bars, mean \pm s.e. (B) Body weight of MIAPaCa-2 tumour-bearing control mice and mice treated with gemcitabine and fluvastatin alone or in combination. No changes or decline in body weight were noted. Symbols and bars, mean \pm s.e.

chemotherapeutic drugs used in pancreas neoplasm, may represent a rational approach to the therapy of advanced pancreatic cancer. Two of these agents, R-115777 and SCH-66336, are orally active heterocyclic compounds and already in phase II/III studies in patients (Dempke, 2003) with advanced pancreatic cancers to determine the extent of their clinical activity. Indeed, durable objective partial responses were noted in several patients (Dempke, 2003). Fluvastatin in our experiments increases the nonisoprenylated form of cellular proteins. Although farnesyl protein transferase inhibitors are currently being evaluated in phase II and III clinical trials (Zhu et al, 2003) and they were found to be well tolerated (Dempke, 2003), there are still no data on their long-term safety. On the other hand, statins have been in clinical use for more than 15 years with a well-known, yet favourable, toxicity profile, even if used for long periods. Fluvastatin has the same toxicity profile as other HMG-CoA reductase inhibitors, while it has not been associated with rhabdomyolysis and myopathy (Scripture and Pieper, 2001). Furthermore, fluvastatin has been safely administered at high doses in paediatric patients with cancer (Lopez-Aguilar et al, 1999). Indeed, micromolar concentrations of gemcitabine and fluvastatin have been reached in human plasma in pharmacokinetic studies (Kroep et al, 1999; Kantola et al, 2000), and these plasma levels are in the range of the antiproliferative activity found in the present study. Moreover, the administered fluvastatin dose in our in vivo experiment was based on the study by Ferrara et al (2003), who showed, for the same total dose given in 14 days, serum concentrations of fluvastatin in mice higher than $1.2 \mu \mathrm{g} \mathrm{ml}^{-1}$, representing drug levels of $\sim 2$ times the mean drug concentration in human plasma after a $40 \mathrm{mg}$ oral dose and confirming the potential translation to the clinic of our data.

The chemotherapeutic activity of gemcitabine is well known (Bergman et al, 1996), and has been confirmed by MIA PaCa2 cells used in this study, whereas the antiproliferative activity of fluvastatin has been previously described only in breast cancer cells (Mueck et al, 2003). Treatment with fluvastatin is associated with tumour cell rounding, followed by cell detachment and apoptosis. This morphological change has also been previously described for the HMGCoA reductase inhibitor lovastatin in vitro on mesangial cells (Ghosh et al, 1997) and attributed to the inhibition of isoprenylation of small GTP-binding proteins that regulates the formation of actin stress fibres and focal adhesion plaques. In particular, in this study, fluvastatin inhibited the 
geranyl-geranylation of $\mathrm{p} 21 \mathrm{rhoA}$, a protein involved in cytoskeletal functions (Evers et al, 2000). Indeed, pancreatic cancer cells treated with fluvastatin accumulate $p 21 r h o A$ in the cytoplasm, as shown by immunocytochemistry, because of the impairment of post-translational processing and lack of membrane association of the peptide.

To our knowledge, the data of the present study are the first findings to demonstrate that fluvastatin has an antiproliferative/ proapoptotic effect on human pancreatic cancer cells. Fluvastatin may induce cells to become more susceptible to apoptosis by inhibiting the isoprenylation process, as demonstrated by the use of mevalonic acid as a pharmacological tool to reverse its antiproliferative and proapoptotic effects. In the combination treatment, fluvastatin increased apoptosis in a synergistic manner. By using the median-effect principle and the CI-isobologram technique, a synergism has been demonstrated between fluvastatin and gemcitabine in vitro, regardless of the schedule of administration, thus allowing for a dose reduction in order to obtain the same effect, with the consequence of lowering the toxicities of each drug in combination. Moreover, the in vivo simultaneous combination greatly inhibits human pancreatic tumours without any remarkable side effect on mice. At the present time, no association studies involving fluvastatin have been published yet; however, it has been previously shown that lovastatin enhanced the apoptosis induced by chemotherapeutic drugs, including 5-FU and cisplatin, in colon cancer cell lines (Agarwal et al, 1999). Furthermore, Holstein and Hohl (2001b) demonstrated synergism between paclitaxel and lovastatin on human cancer cell lines, whereas Feleszko et al (2002) showed an in vivo enhanced antitumour activity of doxorubicin in murine tumour models when associated with lovastatin.

In an effort to better explain the molecular basis of the demonstrated synergistic effects between gemcitabine and fluvastatin, the signal transduction pathway of the isoprenylated proteins and the activating metabolism of gemcitabine were further studied. The signal transduction to ras effectors was interrupted, as demonstrated by the lack of activation in fluvastatin-treated cells of 42MAPK/ERK2, a cytoplasmic serine/threonine proteine kinase, responsible for the transduction of mitogenic signals

\section{REFERENCES}

Abbruzzese JL (2002a) New applications of gemcitabine and future directions in the management of pancreatic cancer. Cancer 95: 941 - 945

Abbruzzese JL (2002b) Past and present treatment of pancreatic adenocarcinoma: chemotherapy as a standard treatment modality. Semin Oncol 29: 2-8

Agarwal B, Bhendwal S, Halmos B, Moss SF, Ramey WG, Holt PR (1999) Lovastatin augments apoptosis induced by chemotherapeutic agents in colon cancer cells. Clin Cancer Res 5: 2223-2229

Barton-Burke M (1999) Gemcitabine: a pharmacologic and clinical overview. Cancer Nurs 22: 176-183

Bergman AM, Ruiz vHV, Veerman G, Kuiper CM, Peters GJ (1996) Synergistic interaction between cisplatin and gemcitabine in vitro. Clin Cancer Res 2: 521 - 530

Bocci G, Danesi R, Marangoni G, Fioravanti A, Boggi U, Esposito I, Fasciani A, Boschi E, Bevilacqua G, Mosca F, Del Tacca M (2004) Antiangiogenic $v s$ cytotoxic therapeutic approaches to human pancreas cancer: an experimental study with a vascular endothelial growth factor receptor-2 tyrosine kinase inhibitor and gemcitabine. Eur J Pharmacol 498: 9-10

Boucher MJ, Morisset J, Vachon PH, Reed JC, Laine J, Rivard N (2000) MEK/ERK signaling pathway regulates the expression of Bcl-2, Bcl-X(L), and Mcl-1 and promotes survival of human pancreatic cancer cells. J Cell Biochem 79: $355-369$

Braakhuis BJ, Ruiz vHV, Boven E, Veerman G, Peters GJ (1995) Scheduledependent antitumor effect of gemcitabine in in vivo model system. Semin Oncol 22: $42-46$
(Kolch, 2002). Indeed, the substitution of fluvastatin with the MAPK/ERK kinase inhibitor PD098059 in combination with gemcitabine produced similar synergistic results as the association of fluvastatin and gemcitabine. These data could suggest that MAPK activity suppression due to fluvastatin (through the isoprenylation inhibition) or PD098059 is a key step to enhance the cancer cell kill of gemcitabine, as also previously suggested (Nelson and Fry, 2001).

Moreover, in our experimental setting, the greater effect of the fluvastatin/gemcitabine combination could also be dependent on a higher concentration and prolonged half-life of the active mono-, di- and triphosphate metabolites of gemcitabine inside the pancreatic tumour cells due to the fluvastatin induction of the expression of dCK, which activates the drug by phosphorylation, and the reduction of $5^{\prime}-\mathrm{NT}$, which removes the phosphate group from cytotoxic metabolites (Danesi et al, 2003).

In conclusion, the results of the present study demonstrate that the combination of gemcitabine and fluvastatin is an effective cytotoxic, proapoptotic treatment in vitro and in vivo against MIAPaCa-2 cells harbouring a mutated p21ras by a mechanism of action mediated, at least in part, by the inhibition of p21ras and rhoA prenylation. As stated recently by Wong et al (2002), 'understanding the molecular mechanism of statin's anti-cancer action remains outstanding' for the clinical management of patients and in this view, our data could contribute to a better understanding of the fluvastatin cytotoxic mechanism of action and to conceive new synergistic combinations in order to maximise the efficacy and minimise the drug-related toxicities in vivo, especially in the field of metastatic pancreatic cancer, where few effective therapeutic choices are presently available.

\section{ACKNOWLEDGEMENTS}

We thank Dr Antonio Marchetti for the mutational analysis of Kras gene, and both Laura Ciofi and Bianca Maria Martelloni for their technical assistance.
Chou TC, Tan QH, Sirotnak FM (1993) Quantitation of the synergistic interaction of edatrexate and cisplatin in vitro. Cancer Chemother Pharmacol 31: 259-264

Cowgill SM, Muscarella P (2003) The genetics of pancreatic cancer. Am J Surg 186: $279-286$

Danesi R, de Braud F, Fogli S, de Pas TM, Di Paolo A, Curigliano G, Del Tacca M (2003) Pharmacogenetics of anticancer drug sensitivity in nonsmall cell lung cancer. Pharmacol Rev 55: 57-103

Danesi R, Figg WD, Reed E, Myers CE (1995) Paclitaxel (Taxol) inhibits protein isoprenylation and induces apoptosis in PC-3 human prostate cancer cells. Mol Pharmacol 47: 1106-1111

Dempke WC (2003) Farnesyltransferase inhibitors - a novel approach in the treatment of advanced pancreatic carcinomas. Anticancer Res 23: $813-818$

Di Paolo A, Danesi R, Nardini D, Bocci G, Innocenti F, Fogli S, Barachini S, Marchetti A, Bevilacqua G, Del Tacca M (2000) Manumycin inhibits ras signal transduction pathway and induces apoptosis in COLO320-DM human colon tumour cells. Br J Cancer 82: 905-912

El Rayes BF, Shields AF, Vaitkevicius V, Philip PA (2003) Developments in the systemic therapy of pancreatic cancer. Cancer Invest 21: 73-86

Etienne-Manneville S, Hall A (2002) Rho GTPases in cell biology. Nature 420: $629-635$

Evers EE, Zondag GC, Malliri A, Price LS, ten Klooster JP, van der Kammen RA, Collard JG (2000) Rho family proteins in cell adhesion and cell migration. Eur J Cancer 36: 1269-1274 
Feleszko W, Mlynarczuk I, Balkowiec-Iskra EZ, Czajka A, Switaj T, Stoklosa T, Giermasz A, Jakobisiak M (2000) Lovastatin potentiates antitumor activity and attenuates cardiotoxicity of doxorubicin in three tumor models in mice. Clin Cancer Res 6: 2044-2052

Feleszko W, Mlynarczuk I, Olszewska D, Jalili A, Grzela T, Lasek W, Hoser G, Korczak-Kowalska G, Jakobisiak M (2002) Lovastatin potentiates antitumor activity of doxorubicin in murine melanoma via an apoptosisdependent mechanism. Int J Cancer 100: $111-118$

Feleszko W, Zagozdzon R, Golab J, Jakobisiak M (1998) Potentiated antitumour effects of cisplatin and lovastatin against MmB16 melanoma in mice. Eur J Cancer 34: 406-411

Ferrara DE, Liu X, Espinola RG, Meroni PL, Abukhalaf I, Harris EN, Pierangeli SS (2003) Inhibition of the thrombogenic and inflammatory properties of antiphospholipid antibodies by fluvastatin in an in vivo animal model. Arthritis Rheum 48: 3272 - 3279

Ghosh PM, Mott GE, Ghosh-Choudhury N, Radnik RA, Stapleton ML, Ghidoni JJ, Kreisberg JI (1997) Lovastatin induces apoptosis by inhibiting mitotic and post-mitotic events in cultured mesangial cells. Biochim Biophys Acta 1359: $13-24$

Giovannetti E, Mey V, Nannizzi S, Pasqualetti G, Marini L, Del Tacca M, Danesi R (2005) Cellular and pharmacogenetics foundation of synergistic interaction of pemetrexed and gemcitabine in human non-small cell lung cancer cells. Mol Pharmacol 68: $110-118$

Heinemann V (2002) Gemcitabine in the treatment of advanced pancreatic cancer: a comparative analysis of randomized trials. Semin Oncol 29: 9-16

Holstein SA, Hohl RJ (2001a) Interaction of cytosine arabinoside and lovastatin in human leukemia cells. Leuk Res 25: 651-660

Holstein SA, Hohl RJ (2001b) Synergistic interaction of lovastatin and paclitaxel in human cancer cells. Mol Cancer Ther 1: 141-149

Jacobs AD (2002) Gemcitabine-based therapy in pancreas cancer: gemcitabine-docetaxel and other novel combinations. Cancer 95: $923-$ 927

Kamat AM, Karashima T, Davis DW, Lashinger L, Bar-Eli M, Millikan R, Shen Y, Dinney CP, McConkey DJ (2004) The proteasome inhibitor bortezomib synergizes with gemcitabine to block the growth of human 253JB-V bladder tumors in vivo. Mol Cancer Ther 3: 279-290

Kantola T, Backman JT, Niemi M, Kivisto KT, Neuvonen PJ (2000) Effect of fluconazole on plasma fluvastatin and pravastatin concentrations. Eur J Clin Pharmacol 56: 225-229

Kaushal V, Kohli M, Mehta P, Mehta JL (2003) Potential anticancer effects of statins: fact or fiction? Endothelium 10: 49-58

Kolch W (2002) Ras/Raf signalling and emerging pharmacotherapeutic targets. Expert Opin Pharmacother 3: 709-718

Kroep JR, Giaccone G, Voorn DA, Smit EF, Beijnen JH, Rosing H, van Moorsel CJ, van Groeningen CJ, Postmus PE, Pinedo HM, Peters GJ
(1999) Gemcitabine and paclitaxel: pharmacokinetic and pharmacodynamic interactions in patients with non-small-cell lung cancer. J Clin Oncol 17: $2190-2197$

Kusama T, Mukai M, Iwasaki T, Tatsuta M, Matsumoto Y, Akedo $\mathrm{H}$, Nakamura H (2001) Inhibition of epidermal growth factor-induced RhoA translocation and invasion of human pancreatic cancer cells by 3hydroxy-3-methylglutaryl-coenzyme a reductase inhibitors. Cancer Res 61: $4885-4891$

Kusama T, Mukai M, Iwasaki T, Tatsuta M, Matsumoto Y, Akedo H, Inoue M, Nakamura H (2002) 3-Hydroxy-3-methylglutaryl-coenzyme a reductase inhibitors reduce human pancreatic cancer cell invasion and metastasis. Gastroenterology 122: $308-317$

Lawrence JM, Reckless JP (2002) Fluvastatin. Expert Opin Pharmacother 3: $1631-1641$

Liang PH, Ko TP, Wang AH (2002) Structure, mechanism and function of prenyltransferases. Eur J Biochem 269: 3339-3354

Liao JK (2002) Isoprenoids as mediators of the biological effects of statins. J Clin Invest 110: $285-288$

Lopez-Aguilar E, Sepulveda-Vildosola AC, Rivera-Marquez H, CerecedoDiaz F, Valdez-Sanchez M, Villasis-Keever MA (1999) Security and maximal tolerated doses of fluvastatin in pediatric cancer patients. Arch Med Res 30: $128-131$

Marchetti A, Buttitta F, Pellegrini S, Chella A, Bertacca G, Filardo A, Tognoni V, Ferreli F, Signorini E, Angeletti CA, Bevilacqua G (1996) Bronchioloalveolar lung carcinomas: K-Ras mutations are constant events in the mucinous subtype. J Pathol 179: 254-259

Mueck AO, Seeger H, Wallwiener D (2003) Effect of statins combined with estradiol on the proliferation of human receptor-positive and receptornegative breast cancer cells. Menopause 10: $332-336$

Nelson JM, Fry DW (2001) Akt, MAPK (Erk1/2), and P38 act in concert to promote apoptosis in response to ErbB receptor family inhibition. $J$ Biol Chem 276: $14842-14847$

Rak J, Kerbel RS (2001) Ras regulation of vascular endothelial growth factor and angiogenesis. Methods Enzymol 333: 267-283

Scripture CD, Pieper JA (2001) Clinical pharmacokinetics of fluvastatin. Clin Pharmacokinet 40: 263-281

Seeger H, Wallwiener D, Mueck AO (2003) Statins can inhibit proliferation of human breast cancer cells in vitro. Exp Clin Endocrinol Diabetes 111: $47-48$

Wong WW, Dimitroulakos J, Minden MD, Penn LZ (2002) HMG-CoA reductase inhibitors and the malignant cell: the statin family of drugs as triggers of tumor-specific apoptosis. Leukemia 16: 508-519

Zhu K, Hamilton AD, Sebti SM (2003) Farnesyltransferase inhibitors as anticancer agents: current status. Curr Opin Investig Drugs 4: $1428-1435$ 